\title{
PERAN BRAND IMAGE DALAM MEMEDIASI PENGARUH ELECTRONIC WORD OF MOUTH TERHADAP NIAT BELI
}

\author{
Ida Bagus Gede Ari Suyoga ${ }^{1}$ \\ I Wayan Santika ${ }^{2}$ \\ ${ }^{1,2}$ Fakultas Ekonomi dan Bisnis Universitas Udayana, Bali, Indonesia \\ e-mail: ibarisuyoga21@yahoo.com
}

\begin{abstract}
ABSTRAK
Makanan merupakan hal yang penting karena merupakan kebutuhan pokok manusia. Richeese Factory adalah sebuah jariangan rumah makan siap saji asal Indonesia dengan menu ayam goreng pedas dengan saus keju yang merupakan anak perusahaan dari Kaldu Sari Nabati. Penelitian ini bertujuan untuk menjelaskan peran brand image dalam memediasi pengaruh electronic word of mouth terhadap niat beli produk Recheese Factory di Denpasar. Pengumpulan data pada penelitian ini menggunakan kuesioner. Jumlah sampel sebanyak 100 responden dan menggunakan teknik non-probability sampling. Teknik analisis yang digunakan dalam penelitian ini adalah teknik anlisis jalur (path analysis). Berdasarkan hasil analisis ditemukan bahwa electronic word of mouth berpengaruh positif dan signifikan terhadap niat beli. Brand image memiliki pengaruh positif dan signifikan terhadap niat beli. Brand image positif dan signifikan memediasi pengaruh antara electronic word of mouth terhadap niat beli. Saran yang dapat diberikan berdasarkan hasil penelitian adalah Richeese Factory harus lebih meningkatkan inovasi dan membuka cabang lebih banyak sehingga akan memberikan dampat atau manfaat yang positif yang lebih bagi konsumen untuk lebih tahu produk yang dimiliki Richeese Factory.
\end{abstract}

Kata kunci: brand image, electric word of mouth, niat beli.

\begin{abstract}
Food is an important thing becuase is a basic human need. Richeese Factory is a fast food restaurant from Indonesia with a menu of spicy fried chicken with cheese sauce which is a subsidiary of Kaldu Sari Nabati. This study aims to explain the role of brand image in mediating the influence of electronic word of mouth on the purchase intention of Recheese Factory products in Denpasar. Data collection in this study using questionnaires. The number of samples is 100 respondents and using non-probability sampling technique. The analysis technique used in this research is path analysis technique Based on the results of the analysis found that electronic word of mouth has a positive and significant effect on purchasing intentions. Brand image has a positive and significant influence on buying intentions. Brand positive and significant image mediates the influence between electronic word of mouth on buying intentions. Suggestions that can be given based on the results of research is Richeese Factory should further increase innovation and open more branches so that will provide more positive dampat or benefits for consumers to better know the products owned Richeese Factory.
\end{abstract}

Kata kunci: brand image, electric word of mouth, purchase intention 


\section{PENDAHULUAN}

Makanan merupakan hal yang penting dimana merupakan kebutuhan pokok manusia. Dapat diketahui kehidupan modern konsumen selektif dalam hal mengkonsumsi makanan yang dimana sangat sulit menemukan hal yang tepat dengan keinginan konsumen. Kebutuhan pangan sebagai kebutuhan dasar, menciptakan suatu peluang usaha dibidang kuliner. Banyak makanan kini hadir untuk dapat memenuhi keinginan dari konsumen yang dimana kebutuhan tersebut sangatlah beragam. Denpasar sebagai Ibu Kota Provinsi Bali memiliki tingkat peluang usaha-usaha di bidang kuliner yang tumbuh sangat pesat. Perkembangan perilaku konsumen dari masa ke masa, memaksa produsen harus melakukan inovasi dan melakukan riset serta pengembangan yang berkelanjutan sehingga produk dan strategi pemasaran yang digunakan dapat diterapkan dengan tepat dan sesuai dengan kondisi pasar.

Makanan yang akan dipilih konsumen haruslah memiliki kualitas dan keamanan, dimana dua elemen yang penting di dalam persepsi konsumen dan pengambilan keputusan yang terkait dengan pilihan makanan (Röhr et al. 2005). Konsumen juga akan berpedoman pada brand image berdasarkan pengalaman mereka, dan juga kualitas layanan yang dirasakan (Aydin and Ozer, 2005). Peluang ini direspon oleh pemilik usaha dalam negeri yang ingin ikut ambil bagian di dalam memenangkan persaingan di pasar saat ini, pemilik restoran telah berupaya menawarkan nilai terbaik untuk makanan mereka dan memberi pelanggan suasana yang memuaskan (Soriano, 2002). Hal tersebut menjamin permintaan yang akan 
terus berlanjut jika nilai produk melebihi harapan dan kepuasan pelanggan (Shaharudin et al. 2010).

Makanan yang dinilai memuaskan akan berdampak pada niat beli konsumen, pada dasarnya niat beli juga bisa didefinisikan sebagai keputusan untuk bertindak atau tindakan psikologis yang menunjukkan perilaku individu sesuai produk (Samin et al. 2012). Niat beli juga bisa dilihat dari apakah barang tersebut bisa menarik perhatian konsumen (Karmela dan Junaedi, 2009). Tjiptono (2005) menjelaskan bahwa niat beli dapat ditingkatkan dengan memperhatikan beberapa faktor antara lain; (1) Faktor Psikis : merupakan faktor yang berasal dari dalam diri konsumen, yaitu motivasi, persepsi, pengetahuan, keyakinan, dan sikap yang ada di dalam diri masing-masing individu. (2) Faktor Sosial : merupakan proses dimana perilaku seseorang dipengaruhi orang lain dan kebudayaan yang ada di sekitarnya seperti ; keluarga, status sosial, dan kelompok acuan. (3) Pemberdayaan Bauran Pemasaran : faktor ini berasal dari perusahaan yang menjadi produsen terhadap produk yang digunakan oleh konsumen yang terdiri atas ; produk, harga, promosi dan distribusi.

Antusiasme dari masyarakat Indonesia khususnya Denpasar dengan adanya makanan yang memiliki cita rasa yang berbeda akan mendapatkan perhatian dari konsumen, dimana ulasan dari postingan konsumen di internet merupakan hal paling penting didalam komunikasi e-WOM (Sen and Lerman, 2007). Seperti namanya didefinisikan sendiri, e-WOM adalah kombinasi dari electronic dan word of mouth, promosi WOM yang dilakukan oleh pelanggan yang puas atas merek yang digunakan dapat secara signifikan mendongkak reputasi merek (Selvina, 
2017). Electronic word of mouth (e-WOM) adalah bentuk pertukaran informasi dan pengetahuan secara online pada media sosial (Charo et al, 2015).

Komunkasi e-WOM menjadi informasi penting untuk konsumen jadi pemasar harus membuat konten untuk membuat loyalitas terhadap sebuah brand (Chang and Ngai, 2011). e-WOM dapat dilihat melalui tiga dimensi yaitu pertama kredibilitas e-WOM, kedua kualitas e-WOM, ketiga yaitu kuantitas e-WOM (Bataineh, 2015). e-WOM dapat menciptakan pernyataan negatif atau positif yang dibuat oleh konsumen aktual, potential atau konsumen sebelumnya mengenai produk atau perusahaan, yang dimana informasi ini tersedia bagi orang-orang ataupun institusi melalui media internet (Thurau et al. 2004). Cheung et al (2009) perusahaan harus aktif terlibat dalam beberapa komunitas online dengan cara memberikan informasi yang relevan dan lengkap tentang perusahaan yang akan menghasilkan sebuah informasi yang lebih baik. Sehingga konsumen akan menjadi lebih jelas mengenai perusahaan dan ini akan mengarah pada e-WOM positif antar konsumen.

Komunikasi e-WOM adalah proses yang dimana konsumen dapat berbagai macam informasi dan pendapat secara langsung untuk pembelian (Jalilvand et al. 2011). Teknologi internet memudahkan konsumen untuk berbagi dan bertukar komentar mereka secara online dengan orang lain tentang pengalaman mereka menggunakan layanan produk (Cheung and Lee, 2012). Melalui review dari konsumen lain dalam sharing review platform dapat mempengaruhi niat beli konsumen (Semuel dan Lianto, 2014). Beberapa kelompok konsumen menggunakan internet sebagai bentuk referensi dengan mengambil pendapat orang 
lain sebagai dasar keputusan pembelian offline mereka, melalui data yang diperoleh secara online (Chatterjee, 2001). Ulasan online telah menjadikan salah satu cara paling popular bagi konsumen untuk mendapatkan informasi, dimana salah satu cara paling efisien bagi perusahaan untuk meningkatkan kesadaran akan brand mereka dan membangun sebuah reputasi (Wu, 2014).

Richeese Factory adalah sebuah jaringan rumah makan siap saji asal Indonesia dengan menu utama ayam goreng pedas dan saus keju yang dimiliki oleh PT Richeese Kuliner Indonesia, anak usaha Kaldu Sari Nabati. Richeese Factory membuka gerai pertamanya di pusat perbelanjaan Paris Van Java, Bandung, pada 8 Februari 2011. Hingga bulan Agustus 2016, restoran ini memiliki 50 gerai yang tersebar di wilayah Jabodetabek, Bandung, Sumedang, Garut, Cirebon, Tegal, Semarang, Surabaya, Malang, dan Denpasar.

Denpasar memiliki peluang bagi usaha-usaha di bidang kuliner yang akan tumbuh pesat dan bervariasi. Untuk mengetahui tempat makanan cepat saji yang digemari oleh masyarakat Kota Denpasar, telah dilakukan studi pendahuluan dengan survei kuesioner kepada masyarakat Kota Denpasar. Jumlah sampel yang diambil sebanyak 30 responden dari masyarakat Kota Denpasar pada Tabel 1.

Tabel 1

Tempat Makanan Cepat Saji Yang Sering di Kunjungi Masyarakat Kota Denpasar

\begin{tabular}{lc}
\hline \multicolumn{1}{c}{ Nama Tempat Makan } & Jumlah Responden (Orang) \\
\hline McDonalds & 12 \\
\hline KFC & 11 \\
\hline Richeese Factory & 7 \\
\hline \multicolumn{1}{c}{ TOTAL } & 30 \\
\hline
\end{tabular}

Sumber : Hasil Studi Pendahuluan, 2017 
Pada Tabel 1., hasil studi pendahuluan survei kuesioner memperlihatkan tempat makanan cepat saji yang paling sering dikunjungi oleh masyarakat di Kota Denpasar. Seperti diketahui, Richeese Factory merupakan tempat makanan cepat saji yang cukup besar di Kota Denpasar. Richeese Factory menghadirkan sajian makanan yang berinovasi dan berkualitas baik. Segmen yang disasar oleh Richeese Factory adalah segala jenis usia yang dimana Richeese Factory harus menjamin produknya agar aman dikonsumsi bagi semua pelanggannya. Kualitas makanan merupakan kunci penting yang selalu dicari oleh pelanggan untuk memenuhi kebutuhan dan harapan mereka terhadap restoran yang mereka pilih (Peri, 2006). Membangun brand image yang tepat dapat dicapai dengan pemasaran yang kuat dengan menonjolkan ciri khas dan kelebihan-kelebihan yang dimiliki oleh produk tersebut (Ravita, 2015).

Salah satunya yaitu Richeese Factory merupakan perusahaan di bidang makanan cepat saji yang spesialisasi di dalam penjualan produk olahan ayam. Richeese Factory pertama kali yang melakukan inovasi berbahan dasar ayam yang memiliki cita rasa yang pedas dan menggunakan keju sebagai saus nya. Seperti sudah diketahui Richeese Factory merupakan anak dari Kaldu Sari Nabati yang sudah terlebih dahulu terkenal dengan makanan ringan yang berbahan dasar keju. Membangun sebuah brand bagi Richeese Factory membutuhkan waktu yang sangat lama dimana brand akan menjadi sebuah investasi bagi perusahaan.

Penelitian terdahulu yang dilakukan oleh (Bian and Moutinho, 2009) meneliti dampak efek langsung dan tidak langsung dari brand image yang dimana keterlibatan produk dan pengetahuan produk terhadap niat beli produk barang 
tiruan, menunjukkan brand image sebagai mediasi yang mempengaruhi keterlibatan atau pengetahuan tentang produk pada niat konsumen untuk membeli. Richeese Factory juga menyediakan web yang dimana terdapat menu baru dan daftar harga dari produknya dan juga Richeese Factory tidak lupa menaruh alamat dari gerai-gerai di kota-kota lainnya. Pada web konsumen bisa melihat menu, memesan produk dan menampung tentang keluhan konsumen agar Richeese Factory dapat lebih meningkatkan yang kurang di dalam pelayanan atau produk yang disediakan. Penelitian terdahulu yang dilakukan oleh (Semuel dan Lianto, 2014) yang menyatakan e-WOM berpengaruh signifikan terhadap niat beli.

Hasil penelitian terdahulu yang dilakukan oleh (Jalilvand, 2012) menyatakan bahwa e-WOM berpengaruh signifikan terhadap brand image khususnya pada pasar konsumen. Hasil penelitian yang dilakukan oleh (Dwi, 2016) mengatakan brand direkomendasikan melalui e-WOM maka akan menimbulkan pengaruh terhadap niat beli. Rumusan masalah dalam penelitian ini sebagai berikut. 1) Bagaimana pengaruh e-WOM terhadap niat beli produk Richeese Factory di Kota Denpasar? 2) Bagaimana pengaruh brand image terhadap niat beli produk Richeese Factory di Kota Denpasar? 3) Bagaimana peran brand image memediasi e-WOM terhadap niat beli produk Richeese Factory di Kota Denpasar?

Kasuma (2012) menyatakan sebelum membuat keputusan akhir, pelanggan terus mencari informasi mengenai setiap perusahaan dan jasa. Karena semakin banyak konsumen saat ini lebih terdidik dalam hal pencarian informasi, dimana banyak mengacu pada pencarian online dan sumber yang diterbitkan sebagai media mengumpulkan informasi tentang perusahaan, produk dan jasa. Niat beli bisa juga 
di definisikan sebagai keputusan untuk bertindak atau tindakan psikologis yang menunjukkan perilaku individu sesuai dengan produk yang di inginkan (Samin et al. 2012).

Menurut Schiffman dan Kanuk (2000) niat beli menunjukkan bahwa konsumen akan mengikuti pengalaman mereka, preferensi dan lingkungan eksternal untuk mengumpulkan informasi, mengevaluasi alternatif, dan membuat keputusan pembelian. Shukla (2010) mengemukakan niat beli dengan beberapa indikator di antaranya: (1) Saya akan membeli produk / merek ini daripada apapun merek lain yang tersedia, (2) Saya bersedia merekomendasikan orang lain untuk membeli produk / merek ini, (3) Saya berniat membeli produk / merek ini dimasa depan.

Cheung and Lee (2012) menyatakan kemajuan teknologi internet memungkinkan konsumen untuk berbagi dan bertukar komentar mereka secara online dengan orang lain tentang pengalaman mereka menggunakan layanan produk. Bentuk komunikasi ini telah di sebut dengan e-WOM. Jalilvand et al. (2011) menyatakan bahwa komunikasi e-WOM adalah proses perijinan konsumen untuk berbagai informasi dan pendapat secara langsung untuk membeli. Beberapa penelitian terkait juga telah menunjukkan bahwa pesan e-WOM merupakan sarana penting dimana konsumen dapat memperoleh informasi tentang produk atau kualitas layanan Chevalier and Mayzlin (2006).

Bambauer-Sachse and Mangold (2011) mengemukakan e-WOM dengan beberapa indikator diantaranya: (1) Saya sering membaca ulasan produk dari konsumen online lainnya untuk mengetahui produk / merek apa membuat kesan 
yang baik kepada orang lain, untuk memastikan saya membeli produk /merek yang benar, (2) Saya sering membaca ulasan dari produk konsumen online lainnya, (3) Saya sering berkonsultasi dengan konsumen lain secara online mengenai ulasan produk untuk membantu memilih produk/merek, (4) Saya sering mengumpulkan informasi dari ulasan produk konsumen online sebelum membeli produk / merek tertentu, (5) Jika saya tidak membaca ulasan produk online konsumen ketika saya membeli sebuah produk / merek, saya khawatir mengenai keputusan saya, (6) Ketika saya membeli produk / merek, ulasan produk konsumen online membuat saya percaya diri untuk membeli produk / merek.

Radji (2009) Brand dapat lebih bermanfaat dibanding suatu hak paten, yang mahal dan sulit untuk dipertahankan. Brand yang memiliki image yang positif di benak konsumen, akan lebih memungkinkan konsumen untuk melakukan keputusan pembelian. Adrianto (2013) menyebutkan brand image adalah presepsi yang bertahan lama dan dibentuk melalui pengalaman dan sifatnya relatif konsisten. Menurut Petrauskaite (2014) mendukung pernyataan ini, dimana dia menyebutkan bahwa keputusan pembelian dapat dirangsang oleh pengetahuan tentang brand dan konsumen lebih cenderung mengandalkan brand image yang akrab bagi mereka.

Menurut Lim (2009) menjelaskan bahwa brand image memiliki pengaruh referensi pada konsumen dalam suatu produk. Ika dan Kustini (2011) mengatakan kualitas yang bagus merupakan identitas produk akan menciptakan aspirasi konsumen rela memilih produk tersebut. Pujadi (2010) mengemukakan bahwa brand image mempengaruhi niat beli dari konsumen. Davis et al, (2009), mengemukakan Brand Image dengan beberapa indikator diantaranya: 
Dibandingkan dengan produk / merek lain, produk / merek ini memiliki kualitas tinggi, (2) Produk / brand ini memiliki sejarah yang kaya, (3) Kita dapat memprediksi dengan andal bagaimana produk / brand ini akan tampil.

Jalilvand (2012) mendapatkan hasil yang dimana e-WOM memiliki pengaruh baik secara langsung maupun tidak langsung terhadap niat beli konsumen. Chang and Ngai (2011) menyatakan bahwa e-WOM memiliki pengaruh yang signifikan terhadap niat beli, selain itu jika e-WOM bersifat logis, persuasif dan didasari atas fakta-fakta mengenai produk maka akan menghasilkan dampak yang positif terhadap niat beli.

Brand image yang ditanamkan di benak konsumenakan menjadi pertimbangan dari konsumen dalam melakukan suatu pembelian Nurmala (2008). Semakin positif brand image dari suatu produk, maka niat konsumen untuk membeli produk tersebut akan semakin tinggi. Jalilvand (2012) menyatakan bahwa brand image memiliki pengaruh secara langsung terhadap niat beli. Wahyuni dan Suparna (2014) mengatakan bahwa brand image berpengaruh positif terhadap niat beli produk tas tiruan di Kota Denpasar. Ini menunjukkan bahwa semakin positif brand image maka semakin tinggi intensi pembelian konsumen.

Hasil riset yang dilakukan Bian and Moutinho (2009) meneliti dampak efek langsung dan tidak langsung dari brand image dimana keterlibatan produk dan pengetahuan produk terhadap niat beli produk barang tiruan. Hasil penelitian tersebut menunjukkan bahwa brand image sebagai mediasi yang mempengaruhi keterlibatan atau pengetahuan tentang produk pada niat konsumen untuk membeli. Hidayanti (2013) Brand image mempunyai pengaruh yang positif dan signifikan 
terhadap niat beli konsumen Krido dan Kemas (2016) di dalam penelitiannya menyatakan bahwa e-WOM memiliki pengaruh positif dan signifikan terhadap brand image. Berdasarkan paparan teori serta penelitian terdahulu dapat disusun hipotesis sebagai jawaban sementara pada penelitian ini sebagai berikut:

H1 : Electronic word of mouth berpengaruh positif dan signifikan terhadap niat beli.

$\mathrm{H} 2$ : Brand image berpengaruh positif dan signifikan terhadap niat beli

H3: Brand Image secara signifikan memediasi pengaruh e-WOM terhadap niat beli

\section{METODE PENELITIAN}

Jenis data yang digunakan dalam penelitan ini adalah jenis data yang dikelompokkan menurut sifatnya, yaitu data kualitatif dan data kuantitatif. Data kualitatif dalam penelitian ini berupa pendapat dari responden mengenai pernyataan yang tertera di dalam kuisioner. Data kuantitatif dalam penelitian ini berupa angka dari jumah gerai Richeese Factory yang ada di Bali.

Adapun sumber data yang digunakan dalam penelitian ini adalah sumber data primer dan sekunder. Sumber primer dalam penelitian ini berasal dari responden yang memberikan tanggapan dalam kuesioner mengenai variabel-variabel dalam penelitian. Sumber sekunder dalam penelitian ini berasal dari institusi yang mempublikasikan data yang dikutip terkait dengan topik penelitian ini, seperti; richeesefactory.com dan media - media yang mempublikasikan data terkait penelitian ini.

Variabel-variabel yang digunakan dalam penelitian ini adalah Variabel bebas adalah variabel yang dianggap memiliki pengaruh terhadap variabel lain. Variabel bebas dalam penelitian ini yaitu e-WOM yang disimbolkan dengan X. 
Variabel mediasi adalah variabel yang dianggap memiliki pengaruh mediasi terhadap variabel lain. Variabel mediasi dalam penelitia ini yaitu Brand Image yang disimbolkan dengan M. Variabel terikat adalah variabel yang dianggap dipengaruhi oleh variabel lain dalam model. Variabel terikat dalam penelitian ini adalah Niat Beli yang disimbolkan dengan Y.

Populasi dari penelitian ini adalah warga Kota Denpasar yang berniat melakukan pembelian di Richeese Factory dalam kurun waktu Agustus-Oktober 2017. Ukuran sampel memegang peranan penting dalam estimasi dan interpretasi hasil. (Sekaran, 2013) menjelaskan ukuran sampel yang baik yakni sampel lebih dari 30 dan kurang dari 500 dan 5-10 kali jumlah variabel atau indikator dalam penelitian. Penelitian ini menggunakan 12 indikator sehingga dengan menggunakan estimasi berdasarkan jumlah parameter diperoleh ukuran sampel sebesar 60-120 responden. Jumlah sampel yang digunakan dalam penelitian ini adalah 100 responden.

Data dalam penelitian ini dikumpulkan melalui penyebaran instrumen penelitian berupa kuisioner. Penyebaran kuisoner dilakukan secara langsung oleh peneliti baik dengan dibantuan google form. Kuesioner terdiri dari pertanyaan terbuka yaitu identitas diri responden dan pernyataan yang berkaitan dengan indikator-indikator penelitian. Pernyataan dalam kuisioner akan diukur dengan menggunakan Skala Likert dengan skala 1 sampai dengan 5 dengan keterangan seperti dalam tabel.

Penelitian ini menggunakan teknik analisis jalur (path analysis) untuk pengolahan data, dimana teknik ini digunakan untuk memprediksi hubungan 
kausalitas antar variabel (model casual) yang telah ditetapkan sebelumnya berdasarkan teori (Utama, 2016:159). Pengolahan data untuk analisis jalur (path analysis) ini akan dikerjakan dengan menggunakan bantuan program SPSS for windows.

\section{HASIL DAN PEMBAHASAN}

Responden dalam penelitian ini berjumlah 100 orang sesuai dengan ukuran sampel. Responden penelitian digambarkan dengan karakteristik responden yang di dasarkan pada variabel demografi yang terdiri dari jenis kelamin beserta pendidikan terakhir yang disajikan pada Tabel 1 . berikut ini.

Tabel 2.

Karakteristik Responden

\begin{tabular}{rcccc}
\hline \multirow{2}{*}{ No } & \multirow{2}{*}{ Kreteria } & \multirow{2}{*}{ Klasifikasi } & Jumlah & Presentase \\
\cline { 3 - 5 } & & & $($ Orang $)$ & $(\%)$ \\
\hline 1 & Jenis kelamin & Laki-Laki & 40 & 40 \\
\hline & Perempuan & 60 & 60 \\
\hline & Jumlah & & $\mathbf{1 0 0}$ & $\mathbf{1 0 0}$ \\
\hline 2 & Pendidikan Terakhir & SMA & 60 & 60 \\
\hline & Jumlah & & 40 & 40 \\
\hline & & $\mathbf{1 0 0}$ & $\mathbf{1 0 0}$ \\
\hline
\end{tabular}

Sumber: Data primer diolah, 2017

Tabel 2., dapat dilihat bahwa hasil didominasi oleh responden berjenis kelamin perempuan yaitu sebesar 60 persen. Hasil tersebut tentu lebih besar dari hasil pada jenis kelamin laki-laki sebesar 40 persen. Hasil pada klasifikasi berdasarkan tingkat pendidikan menunjukan didominasi oleh tingkat pendidikan terakhir SMA yaitu sebesar 60 persen dengan kisaran umur 19 sampai dengan 22 tahun. Sedangkan untuk jenjang pendidikan terakhir perguruan tinggi diperoleh sebesar 40 persen. 
Pengujian validitas tiap butir digunakan analisis item yaitu mengkorelasi skor tiap item dengan skor total item. Untuk mencari hasil ini digunakan sebanyak 30 responden. Nilai korelasi antar skor item dengan total item kemudian dibandingkan dengan $\mathrm{r}$ kritis. Jika korelasi item terhadap skor total lebih besar dari r kritis $(0,30)$ maka instrumen dikatakan valid. Berikut hasil uji validitas pada Tabel 3.

Tabel 3. Hasil Uji Validitas

\begin{tabular}{ccccc}
\hline No & Variabel & $\begin{array}{c}\text { Item } \\
\text { Pernyataan }\end{array}$ & $\begin{array}{c}\text { Koefisien } \\
\text { Korelasi }\end{array}$ & Keterangan \\
\hline 1 & Niat Beli & Y1 & 0,918 & Valid \\
\hline & $($ Y $)$ & Y2 & 0,906 & Valid \\
\hline 2 & $e-$ WOM & Y3 & 0,957 & Valid \\
\hline & & X2 & 0,929 & Valid \\
\hline & $(\mathrm{X})$ & X3 & 0,914 & Valid \\
\hline & & X4 & 0,908 & Valid \\
\hline 3 & Brand Image & M1 & 0,933 & Valid \\
\hline & (M) & M2 & 0,967 & Valid \\
\hline & & M3 & 0,909 & Valid \\
\hline
\end{tabular}

Sumber: Data diolah, 2017

Berdasarkan uji validitas instrumen penelitian pada Tabel 3. menunjukan bahwa seluruh indikator pernyataan dalam variabel niat beli, brand image dan eWOM menggunakan kembali memiliki pearson correlation yang lebih besar dari 0,3 sehingga seluruh indikator tersebut telah memenuhi syarat validitas data.

Tabel 4. menyajikan hasil uji relibilitas instrumen penelitian untuk menetapkan apakah instrumen kuesioner dapat digunakan lebih dari satu kali, dengan responden yang sama yaitu 30 responden. 
Tabel 4.

Hasil Uji Relibilitas

\begin{tabular}{ccc}
\hline Variabel & Cronbach's Alpha & Keterangan \\
\hline Niat Beli & 0,917 & Reliabel \\
\hline e-WOM & 0,959 & Reliabel \\
\hline Brand Image & 0,903 & Reliabel \\
\hline
\end{tabular}

Sumber: Data diolah, 2017

Tabel 4., tersebut menunjukan bahwa ketiga instrumen penelitian yaitu variabel Niat Beli, e-WOM, dan Brand image memiliki koefisien Cronbach's Alpha $>$ 0,60 sehingga pernyataan pada kuesioner tersebut reliabel. Kuesioner berisi pertanyaan yang mengambarkan penilaian dari responden mengenai variabelvariabel yang terdapat di dalam penelitian Sugiyono (2010). Jawaban dari responden digolongkan ke dalam beberapa skala pengukuran dengan kriteria yang mengacu pada skor rata-rata jawaban responden yang di distribusikan kembali menjadi berikut:

$$
\begin{aligned}
& 1,00-1,80=\text { Sangat Rendah } \\
& 1,81-2,60=\text { Rendah } \\
& 2,61-3,40=\text { Cukup Tinggi } \\
& 3,41-4,20=\text { Tingi } \\
& 4,21-5,00=\text { Sangat Tinggi }
\end{aligned}
$$

Variabel niat beli menggunakan 3 pertanyaan untuk mengetahui jawaban responden yang ada di Kota Denpasar mengenai niat beli Richeese Factory yang dimana dapat dilihat perhitungannya pada Tabel 5. 
Tabel 5.

Deskripsi Jawaban Responden Mengenai Varibel Niat Beli

\begin{tabular}{|c|c|c|c|c|c|c|c|c|}
\hline \multirow{2}{*}{ No } & \multirow{2}{*}{ Pernyataan } & \multicolumn{5}{|c|}{ Distribusi Jawaban } & \multirow{2}{*}{$\begin{array}{l}\text { Rata- } \\
\text { rata }\end{array}$} & \multirow{2}{*}{ Ket } \\
\hline & & 1 & 2 & 3 & 4 & 5 & & \\
\hline 1 & $\begin{array}{l}\text { Saya akan membeli produk Richeese Factory, } \\
\text { dari pada produk makanan cepat saji lainnya yang } \\
\text { tersedia. }\end{array}$ & 0 & 16 & 16 & 12 & 56 & 4,08 & Tinggi \\
\hline 2 & $\begin{array}{l}\text { Saya mau merekomendasikan orang lain untuk } \\
\text { membeli produk Richeese Factory. }\end{array}$ & 0 & 17 & 18 & 23 & 42 & 3,90 & Tinggi \\
\hline 3 & $\begin{array}{l}\text { Saya berniat untuk membeli produk Richeese } \\
\text { Factory ini dimasa yang akan datang. }\end{array}$ & 0 & 18 & 9 & 26 & 47 & 4,02 & Tinggi \\
\hline & Total skor rata-rata & & & & & & 4,00 & Tinggi \\
\hline
\end{tabular}

Sumber: Data Diolah, 2017

Tabel 5., menunjukan bahwa tiga pernyataan mengenai niat beli calon konsumen Richeese Factory memperoleh nilai rata-rata sebesar 4,00 sehingga masuk dalam kreteria tinggi. Dari hasil tersebut terlihat niat beli Richeese Factory di Kota Denpasar mendapatkan respon yang baik dari calon pelanggan. Nilai ratarata tertinggi sebesar 4,08 didapatkan dari pernyataan pertama yaitu "Saya akan membeli produk Richeese Factory, dari pada produk makanan cepat saji lainnya yang tersedia ". Hal tersebut berarti calon pelanggan mempunyai niat beli yang baik terhadap Richeese Factory daripada makanan cepat saji lainnya.

Variabel e-WOM menggunakan enam pernyataan untuk mengetahui jawaban responden yang ada di Kota Denpasar mengenai Richeese Factory yang dimana hasil dari perhitungannya dapat dilihat pada Tabel 6.

Tabel 6., menunjukan bahwa enam pernyataan mengenai e-WOM konsumen di Kota Denpasar memperoleh hasil nilai rata-rata sebesar 4,02 sehingga masuk dalam kreteria tinggi. Dari hasil tersebut terlihat e-WOM dari Richeese Factory di Kota Denpasar mendapatkan respon yang baik dari calon pelanggan. Nilai rata-rata tertinggi sebesar 4,09 didapatkan dari pernyataan pertama yaitu 
"Saya sering membaca review online dari konsumen lain, untuk mengetahui apakah produk Richeese Factory memberikan kesan yang baik terhadap pelanggan lain”. Hal tersebut berarti calon konsumen mempunyai ketertarikan terhadap Richeese Factory dengan mencari informasi mengenai produk dari Richeese Factory.

Tabel 6. Deskripsi Jawaban Responden Mengenai Variabel e-WOM

\begin{tabular}{|c|c|c|c|c|c|c|c|c|}
\hline \multirow{2}{*}{ No } & \multirow{2}{*}{ Pernyataan } & \multicolumn{5}{|c|}{ Distribusi Jawaban } & \multirow{2}{*}{$\begin{array}{l}\text { Rata- } \\
\text { Rata }\end{array}$} & \multirow{2}{*}{ Ket } \\
\hline & & 1 & 2 & 3 & 4 & 5 & & \\
\hline \multirow[t]{2}{*}{1} & Saya sering membaca review online dari & & & & & & & \\
\hline & $\begin{array}{l}\text { konsumen lain, untuk mengetahui apakah } \\
\text { produk Richeese Factory memberikan kesan } \\
\text { yang baik terhadap pelanggan lain }\end{array}$ & 0 & 16 & 10 & 23 & 51 & 4,09 & Tinggi \\
\hline \multirow[t]{2}{*}{2} & $\begin{array}{l}\text { Untuk memastikan saya membeli varian } \\
\text { makanan cepat saji yang tepat dari produk }\end{array}$ & & & & 22 & 48 & 404 & Tinori \\
\hline & $\begin{array}{l}\text { Richeese Factory, saya sering membaca } \\
\text { review online produk tersebut }\end{array}$ & 0 & 14 & 10 & 22 & 48 & 4,04 & 1 1ingg1 \\
\hline \multirow[t]{2}{*}{3} & Saya sering mencari keterangan lewat & & & & & & & \\
\hline & $\begin{array}{l}\text { review online mengenai varian dari produk } \\
\text { Richeese Factory, dimana hal ini dapat } \\
\text { membantu saya memilih produk yang tepat }\end{array}$ & 0 & 16 & 15 & 21 & 48 & 4,01 & Tinggi \\
\hline 4 & $\begin{array}{l}\text { Saya sering mengumpulkan informasi dari } \\
\text { review online yang ada, sebelum saya } \\
\text { membeli produk Richeese Factory }\end{array}$ & 0 & 18 & 13 & 17 & 52 & 4,03 & Tinggi \\
\hline \multirow[t]{2}{*}{5} & Jika saya tidak membaca review online & & & & & & & \\
\hline & $\begin{array}{l}\text { terlebih dahulu sebelum membeli produk } \\
\text { Richeese Factory, membuat saya khawatir } \\
\text { mengenai keputusan saya }\end{array}$ & 0 & 18 & 13 & 28 & 41 & 3,92 & Tinggi \\
\hline \multirow[t]{3}{*}{6} & Ketika saya membeli produk Richeese & & & & & & & \\
\hline & $\begin{array}{l}\text { Factory, review online membuat saya } \\
\text { percaya untuk membeli produk ini }\end{array}$ & 0 & 14 & 17 & 16 & 53 & 4,08 & Tinggi \\
\hline & Total skor rata-rata & & & & & & 4,02 & Tinggi \\
\hline
\end{tabular}

Variabel brand image menggunakan tiga pernyataan untuk mengetahui jawaban dari responden yang ada di Kota Denpasar mengenai brand image yang di miliki oleh Richeese Factory yang perhitungan hasil penelitiannya dapat dilihat pada Tabel 7. 
Tabel 7.

Deskripsi Jawaban Responden Mengenai Variabel Brand Image

\begin{tabular}{|c|c|c|c|c|c|c|c|c|}
\hline \multirow{2}{*}{ No } & \multirow{2}{*}{ Pernyataan } & \multicolumn{5}{|c|}{ Distribusi Jawaban } & \multirow{2}{*}{$\begin{array}{l}\text { Rata- } \\
\text { rata }\end{array}$} & \multirow{2}{*}{ Ket } \\
\hline & & 1 & 2 & 3 & 4 & 5 & & \\
\hline 1 & $\begin{array}{l}\text { Dibandingkan dengan produk makanan } \\
\text { cepat saji lainnya, produk Richeese } \\
\text { Factory memiliki kualitas tinggi }\end{array}$ & 0 & 16 & 16 & 17 & 51 & 4,03 & Tinggi \\
\hline 2 & $\begin{array}{l}\text { Richeese Factory dari awal berdiri hingga } \\
\text { saat ini memiliki sejarah yang sangat } \\
\text { panjang }\end{array}$ & 0 & 14 & 18 & 21 & 47 & 4,01 & Tinggi \\
\hline 3 & $\begin{array}{l}\text { Konsumen dapat memprediksi bagaimana } \\
\text { produk Richeese Factory ini akan tampil } \\
\text { lebih baik untuk masa yang akan dating }\end{array}$ & 0 & 16 & 16 & 28 & 40 & 3,92 & Tinggi \\
\hline & Total skor rata-rata & & & & & & 4,00 & Tinggi \\
\hline
\end{tabular}

Tabel 7. menunjukan bahwa tiga pertanyaan mengenai brand image konsumen di Kota Denpasar memperoleh nilai rata-rata rata sebesar 4,00 sehingga masuk dalam kreteria baik. Dari hasil tersebut terlihat brand image dari Richeese Factory di Kota Denpasar mendapatkan respon yang baik dari calon pelanggan. Nilai rata-rata tertinggi sebesar 4,03 didapatkan dari pernyataan pertama yaitu " Dibandingkan dengan produk makanan cepat saji lainnya, produk Richeese Factory memiliki kualitas tinggi ". Hal tersebut berarti calon konsumen mengetahui kualitas yang diberikan oleh Richeese Factory dari brand image yang dibangun dari awal hingga saat ini.

Uji Kaiser Meyer Olkin digunakan dengan tujuan untuk mengetahui kecukupan sampel. Analisis faktor dianggap layak apabila besaran KMO memiliki nilai minimal 0,5. Berikut hasil uji Kaiser Meyer Olkin (KMO) dapat dilihat pada Tabel 8. 
Hasil uji yang ditunjukan pada Tabel 8. memperlihatkan semua variabel memiliki $\mathrm{KMO}>$ 0,5. Hal ini menyimpulkan bahwa masing-masing variabel memiliki kecukupan untuk analisis faktor.

Tabel 8.

Hasil Uji KMO

\begin{tabular}{|c|c|c|}
\hline No & Variabel & $\mathrm{KMO}$ \\
\hline 1 & Niat Beli & 0,747 \\
\hline 2 & Electronic Word of Mouth & 0,930 \\
\hline 3 & Brand Image & 0,760 \\
\hline
\end{tabular}

Sumber: Data diolah, 2017

Nilai MSA yang diperoleh dari masing-masing variabel akan dimuat pada

Tabel 9., dimana nilai masing-masing variabel lebih besar dari 0,5. Hal ini berarti masing-masing model layak digunakan dalam analisis faktor.

Tabel 9.

Nilai MSA

\begin{tabular}{ccc}
\hline No & Variabel & Nilai MSA \\
\hline $\mathrm{Y}$ & $\mathrm{Y} 1$ & 0,758 \\
\hline & $\mathrm{Y} 2$ & 0,811 \\
\hline $\mathrm{Y} 3$ & $\mathrm{X} 1$ & 0,688 \\
\hline & $\mathrm{X} 2$ & 0,933 \\
\hline & $\mathrm{X} 3$ & 0,931 \\
\hline & $\mathrm{X} 4$ & 0,902 \\
\hline & $\mathrm{X} 5$ & 0,950 \\
\hline $\mathrm{X} 6$ & 0,937 \\
\hline & $\mathrm{M} 1$ & 0,928 \\
\hline & $\mathrm{M} 2$ & 0,794 \\
\hline & $\mathrm{M} 3$ & 0,760 \\
\hline
\end{tabular}

Sumber: Data diolah, 2017

Hasil dari percentage of variance menjelaskan kemampuan dari masingmasing faktor untuk menjelaskan variasinya. Data nilai percentage of variance disajikan pada Tabel 10., dimana nilai percentage of variance masing-masing variabel sudah lebih besar dari 60 persen. 
Tabel 10.

Nilai Percentage of Variance

\begin{tabular}{clc}
\hline No & \multicolumn{1}{c}{ Variabel } & Percentage of Variance \\
\hline 1 & Niat Beli $(\mathrm{Y})$ & 88,334 \\
\hline 2 & Electronic Word of Mouth $(\mathrm{X})$ & 86,178 \\
\hline 3 & Brand Image $(\mathrm{M})$ & 86,777 \\
\hline
\end{tabular}

Sumber: Data diolah, 2017

Dalam penelitian ini teknik analisis yang digunakan adalah teknik analisis jalur (path analysis). Analisis jalur digunakan untuk menentukan pola hubungan antara tiga atau lebih dan tidak dapat dapat digunakan untuk mengkonfirmasi atau menolak hipotesis. Berikut adalah hasil dari analisis jalur dalam penelitian ini :

Perhitungan koefisien Path dilakukan dengan analisis regresi melalui software (SPSS) 17.0 for Windows diperoleh dari hasil yang ditunjukan pada Tabel 10.

Tabel 11. Hasil Analisis Jalur Persamaan Regresi 1

\begin{tabular}{cccc}
\hline \multirow{2}{*}{ Model } & R Square & Standardized Coefficients & Sig. \\
\hline e-WOM & 0,601 & Beta & 0,000 \\
\hline
\end{tabular}

Sumber: Data diolah, 2017

Berdasarkan dari hasil analisis jalur substruktur 2 seperti tang disajikan pada

Tabel 11., maka persamaan strukturalnya adalah sebagai berikut:

$$
\mathrm{Y}=0,776 \mathrm{X}+\mathrm{e}
$$

Tabel 12.

Hasil Analisis Jalur Persamaan Regresi 2

\begin{tabular}{cccc}
\hline Model & R Square & $\begin{array}{c}\text { Standardized Coefficients } \\
\text { Beta }\end{array}$ & Sig. \\
\hline e-WOM & \multirow{2}{*}{0,859} & 0,316 & 0,000 \\
\cline { 3 - 4 } Brand Image & & 0,660 & 0,000 \\
\hline Sumber: Data diolah, 2017 & & &
\end{tabular}


Ida Bagus Gede Ari Suyoga dan I Wayan Santika. Peran Brand Image...

Berdasarkan hasil analisis jalur substruktural 2 seperti yang disajikan pada Tabel 12, maka persamaan strukturalnya adalah sebagai berikut:

$$
\mathrm{Y}=0,316 \mathrm{X}+0,660 \mathrm{M}+\mathrm{e}
$$

Menguji nilai koefisien determinasi $\left(\mathrm{R}^{2}\right)$ dan variabel error (e). Berdasarkan model substruktural 1 dan model substruktural 2, maka dapat disusun model diagram jalur akhir. Sebelum menyusun model diagram jalur akhir, terlebih dahulu dihitung nilai standar error sebagai berikut:

$$
\begin{aligned}
& \mathrm{e} 1=\sqrt{1-R} 1^{2}=\sqrt{1-0,601}=0,631 \\
& \mathrm{e} 2=\sqrt{1-R} 2^{2}=\sqrt{1-0,859}=0,375
\end{aligned}
$$

Berdasarkan perhitungan pengaruh error (e), didapatkan hasil pengaruh error $\left(\mathrm{e}_{1}\right)$ sebesar 0,631 dan pengaruh error $\left(\mathrm{e}_{2}\right)$ sebesar 0,375 .

Hasil koefisien determinansi total adalah sebagai berikut:

$$
\begin{aligned}
\mathrm{R}^{2} \mathrm{M} & =1-\left(\mathrm{Pe}_{1}\right)^{2}\left(\mathrm{Pe}_{2}\right)^{2} \\
& =1-(0,631)^{2}(0,375)^{2} \\
& =1-(0,398)(0,140) \\
& =1-0,055 \\
& =0,945
\end{aligned}
$$

Nilai determinasi total sebesar 0,945 mempunyai arti bahwa sebesar 94,5 persen variasi niat beli dipengaruhi oleh variasi e-WOM dan variasi brand image, sementara sisanya sebesar 5,5 persen dijelaskan oleh factor lain yang dimana tidak dimasukkan ke dalam model. 
Berdasarkan hasil analisis pengaruh e-WOM terhadap niat beli diperoleh nilai Sig t sebesar 0,000 dengan nilai koefisien beta sebesar 0,361. Nilai Sig t 0,000 $<0,05$ mengindikasikan bahwa $\mathrm{H}_{0}$ ditolak dan $\mathrm{H}_{1}$ diterima. Hasil ini mempunyai arti bahwa e-WOM berpengaruh positif dan sigifikan terhadap niat beli.

Berdasarkan hasil analisis pengauh e-WOM terhadap brand image diperoleh nilai Sig t sebesar 0,000 dengan nilai koefisien beta sebesar 0,776. Nilai Sig. t 0,000 $<0,05$ mengindikasikan bahwa $\mathrm{H}_{0}$ ditolak dan $\mathrm{H}_{2}$ diterima. Hasil ini mempunyai arti bahwa e-WOM berpengaruh positif terhadap brand image .

Berdasrkan hasil analisis pengaruh brand image terhadap niat beli diperoleh nilai Sig t sebesar 0,000 dengan nilai koefisien beta sebesar 0,660. Nilai Sig t 0,000 $<0,05$ mengindikasikan bahwa $\mathrm{H}_{0}$ ditolak dan $\mathrm{H}_{3}$ diterima. Hasil ini mempunyai arti bahwa brand image berpengaruh positif dan signifikan terhadap niat beli.

Uji Sobel merupakan alat analisis untuk menguji signifikansi dari hubungan tidak langsung antara variabel eksogen dengan variabel endogen yang dimediasi oleh variabel intervening. Pada penelitian ini uji sobel dilakukan untuk mengetahui peran brand image dalam memediasi hubungan antara pengaruh variabel e-WOM terhadap niat beli di Richeese Factory di Denpasar. Sebelumnya uji sobel dapat dirumuskan dengan menggunakan persamaan sebagai berikut:

$$
Z=\frac{a b}{\sqrt{a^{2} s_{b}^{2}+b^{2} s_{a}^{2}+s_{a}^{2} s_{b}^{2}}}
$$

Keterangan:

$Z$ = nilai kalkulasi sobel.

$\mathrm{a}=$ koefisien regresi dari variabel eksogen $(\mathrm{X})$ terhadap variabel intervening 
(M).

$\mathrm{S}_{\mathrm{a}}=$ varian dari $\mathrm{a}$.

$\mathrm{b}=$ koefisien regresi dari variabel intervening $(\mathrm{M})$ terhadap variabel endogen (Y). $\mathrm{sb}=$ varian dari $\mathrm{b}$.

Bila nilai kalkulasi Z lebih besar dari 1,96 (dengan tingkat kepercayaan 95\%), maka variabel intervening dinilai secara signifikan memediasi hubungan antara variabel eksogen dengan variabel endogen. Secara rinci, perhitungan uji sobel dalam penelitian ini dapat dijelaskan sebagai berikut:

$$
\begin{gathered}
Z=\frac{0,512}{\sqrt{0,03612+0,027878+0,000015}} \\
Z=8,13178
\end{gathered}
$$

Hasil uji sobel untuk penelitian ini menunjukan bahwa hasil tabulasi $\mathrm{Z}=$ $8,13>1,96$ dengan tingkat signifikansi $0,000<0,05$ yang berarti variabel mediasi yakni brand image dinilai secara signifikan mampu memediasi pengaruh e-WOM terhadap niat beli Richeese Factory di Denpasar.

\section{SIMPULAN DAN SARAN}

Simpulan dari penelitian ini serta pembahasan mengenai pengaruh masingmasing variabel yang telah dipaparkan, maka dapat ditarik kesimpulan bahwa variabel e-WOM berpengaruh positif dan signifikan terhadap niat beli pada Richeese Factory di Denpasar, hal tersebut membuktikan bahwa apabila semakin baik e-WOM yang dilakukan perusahaan di media sosial maka akan menimbulkan niat beli dari calon konsumen. 
Variabel e-WOM berpengaruh positif dan signifikan terhadap brand image pada Richeese Factory di Denpasar, hal tersebut membuktikan bahwa jika semakin baik e-WOM yang dilakukan, maka akan membuat brand image yang berbeda daripada tempat makanan cepat saji lainnya.

Variabel brand image berpengaruh positif dan signifikan terhadap niat beli Richeese Factory di Denpasar. Hasil tersebut membuktikan bahwa apabila semakin baik brand image dari sebuah produk, maka calon konsumen akan berniat untuk membeli produk tersebut.

Variabel brand image secara signifikan memediasi pengaruh e-WOM terhadap niat beli Richeese Factory di Denpasar. yang berarti bahwa e-WOM yang dilakukan konsumen akan berdampak pada brand image sehingga memunculkan niat beli dari konsumen pada produk tersebut.

Saran yang dapat diberikan berkaitan dengan penelitian ini sebagai bahan pertimbangan serta masukan yang berguna bagi Richeese Factory dimasa yang akan datang adalah manajemen hendaknya lebih memperhatikan peningkatan promosi di media sosial yang dilakukan, karena promosi yang baik akan menimbulkan keinginan atau niat beli konsumen. Hal tersebut bisa dilakukan dengan mencantumkan review online dari konsumen yang sudah melakukan pembelian pada produk tersebut, agar calon konsumen mendapatkan informasi dan tertarik untuk melakukan pembelian setelah membaca review online pada produk tersebut.

Manajemen harus mampu memprediksi makanan seperti apa yang sebaiknya dapat membuat calon konsumen bertahan, lebih baiknya lagi apabila bisa 
menggait konsumen baru untuk membeli produk tersebut, karena sangat susah untuk membuat konsumen agar tetap mimilih produk tersebut jika banyaknya peniru dalam segi produk yang sama.

Bagi peneliti selanjutnya, diharapkan untuk melakukan penelitian dengan cakupan yang lebih luas, menambah variabel-variabel lain dimana dapat digunakan yaitu repurchase intention, presepsi kualitas, motivasi, loyalitas konsumen, dan kualitas pelayanan.

\section{REFERENSI}

Aydin, S., and Ozer, G.2005. The analysis of antecedents of customer loyalty in the Turkish mobile telecommunication market. European Journal of Marketinng, Vol. 5(3), pp.27.

Bataineh, A. Q.2015. The Impact of Perceived e-WOM on Purchase Intention : The Mediating Role of Corporate Image. International Journal of Marketing Studies, Vol. 7(1), pp.126-136.

Bian, X. and Moutinho, L.2011.The Role of Brand Image, Product Involvement, and Knowledge In Explaining Consumer Purchase Behaviour of Counterfeits: Direct and Indirect Effect. European Journal of Marketing, Vol. 45(2), pp.191.

Bambauer-Sachse, Silke and Sabrina Mangold.2011. Brand equity dilution through negative online word-of-mouth communication. Journal of Retailing and Consumer Services Vol.18, pp.38-45.

Cahyono, Krido Eko., dan Kemaz Abdul Gaffar Aziz. 2016. Pengaruh e-WOM Pada Citra Merek Dan Niat Pembelian (Studi : Mitshubishi Pajero Sport). Jurnal Manajemen \& Kewirausahaan. Sekolah Tinggi Ilmu Ekonomi Indonesia (STIESIA) Surabaya. Vol. 1 No. 2

Chan, Y and Ngai.2011. Conceptualising electronic word of mouth activity An input-process-output perspective, Marketing Intelegence and Planning, Vol 29(5), pp.488-516.

Charo, Naimatullah., Pershant Sharma, Saadullah Shaikh, Abdul Haseeb and Muhammad Zohaib Sufya.2015. Determining the Impact of Ewom on Brand Image and Purchase Intention through Adoption of Online Opinions. International Journal of Humanities and Management Sciences (IJHMS) Vol 3 (1), pp.2320-4044. 
Chatterjee, P.2001. Online reviews: Do consumers use them?, Advances in Consumer Research,Vol. 28, (1), pp.129-133.

Cheung, M.Y., Chuan L , Choon L.S and Huaping C. 2009. Credibility of Electronic Word-of-Mouth: Informational and Normative Determinants of On- line Consumer Recommendations, International Journal of Electronic Commerce, Vol. 13, (4), pp.9-38.

Cheung, C. M., Lee, M. K.2012. What drives consumers to spread electronic word of mouth in online consumer-opinion platforms, pp.218-225.

Chevalier, J. A., and Mayzlin, D. 2006. The effect of word of mouth on sales online book reviews. Journal of Marketing Research, Vol. 43(3), pp. 345-354.

Davis, Donna F., Susan L. Golicic, and Adam Marquardt. 2009.Measuring brand equity for logistics services. The International Journal of Logistics Management. Vol. 20 (2) 2009 pp. 201-212.

Thurau, thorsten hennig, Gwinner, K.P., Walsh, G., and Gremier, D.D. 2004. ElectronicnWord-of- Mouth Via Consumer-Opinion Platforms: What Motives Consumers to Articulate Themselves On the Intenet. Journal of Interactive Marketing. 18(1).

Idris, Hendra Noky Andrianto. 2013. Pengaruh Kualitas Produk, Citra Merek, Harga Dan Promosi Terhadap Keputusan Pembelian Mobil Jenis MPV Merek Toyata Kijang Innova Di Semarang . Diponegoro Journal Of Management, 2 (3), pp.1-10.

Jalilvand, M.R., and N. Samiei, 2012. The effect of electronic word of mouth on brand image and purchase intention An empirical study in the automobile industry in Iran. Marketing Intelligence \& Planning Vol. 30 No. 4, 2012 pp.460-476.

Jalilvand, M.R., S.S. Esfahani and N. Samiei, 2011. Electronic word-of-mouth : Challages and opportunities. Procedia Comput. Sci., Vol 3 pp.42-46.

Kasuma, J. 2012. Micro-enterprise Owners' Loyalty towards their favourite bank: A conceptual framework. Jurnal Manajemen dan Kewirausahawaan, vol. 14(1), pp.1-6.

Karmela, Lili F., dan Junaedi, Jujun. 2009. Pengaruh Store Atmosphere Terhadap Minat Beli Konsumen Pada Toserba Griya Kuningan, Lembaga Ilmu Pendidikan Indonesia. Jurnal Fakultas Komunikasi dan Bisnis Universitas Telkom Bandung Vol. 5 No.9, 2009.

Lim,Yu M. 2009. Customer-based brand equity for a destination: The Effect of Destination Image on Preference for Products Associated with a 
Destination Brand. Thesis Faculty of the Virginia Polytechnic Institute and State University.

Nurmala. 2008. "Pengaruh Iklan Televisi Terhadap Minat Beli Sabun Mandi Pada Mahasiswa Fakultas Ekonomi Universitas Malikussaleh." Jurnal terakreditasi SK Dirjen Dikti No. 43/Dikti/Kep/2008. ISSN: 1693-5241

Nugroho, Dwi Prasetyo. 2016. Analisis Pengaruh e-WOM, Citra Merek, Kepercayaan Merek Terhadap Minat Beli Produk Smartphone Xiaomi Pada Mahasiswa Universitas Muhammadiyah Yogyakarta. Jurnal Manajemen, Universitas Muhammadiyah Yogyakarta.

Petrauskaite, E. 2014. Effect of brand image on consumer purchase behavior: International footware comparison. Thesis Aalborg: Aalborg University.

Peri, C. 2006. The universe of food quality. Food Quality and Preference, Vol. 17 pp.3-8.

Pelupessy, Selvina Juliana, Made Wardana dan Ni Wayan Sri Suprapti. 2017. Peran Brand Image Dalam Memediasi Pengaruh Wom Terhadap Switching Intention Ke Produk Smartphone Merek Samsung Di Denpasar. E-Jurnal Ekonomi dan Bisnis Universitas Udayana, ISSN : 2337-3067

Pujadi, Bambang SE. 2010. Studi Tentang Pengaruh Citra Merek Terhadap Minat Beli Melalui Sikap Terhadap Merek Thesis Universitas Diponegoro.

Radji, Djoko Lesmana. 2009. Hubungan Citra Merek, Kepuasan dan Loyalitas Konsumen. Jurnal Bisnis dan Manajemen. Vol.10 (1) 17-34.

Röhr, A., Lu'ddecke, A., Drusch, S., Muller, M.J. and Alvensleben, R.V. 2005. Food quality and safety - Consumer perception and public health concern. Food Control, Vol.16, pp.649-655.

Sen, S. and Lerman, D. 2007, "Why are you telling me this? An examination into negative consumer reviews on the web", Journal of Interactive Marketing, Vol. 21 No. 4, pp.76-94.

Shukla, Paurav. 2010. Impact of interpersonal influences, brand origin and brand image on luxury purchase intentions: Measuring interfunctional interactions and a cross-national comparison. Journal of World Business Vol. 46 (2011) pp.242-252

Schiffman, L.G. and Kanuk, L.L. 2007. Consumer behaviour. Singapore: Prentice Hall International.

Soriano, D.R. 2002. Customers' expectations factors in restaurants. The situation in Spain. International Journal Quality \& Reliability Management, Vol. 19 ISSN (8/9), pp.1055-1067. 
Shaharudin, M.R., Hassan, A.A., Mansor, S.W Elias, S.J., Harun, E.H., and Abdul, N.A. 2010. The relationship between extrinsic and intrinsic attributes of product quality with brand loyalty on Malaysia national brand Motorcycle/Scooter, MODENAS. Interdisciplinary Journal of Contemporary Research in Business. Vol. 6, No. 3, 2010, ISSN 17128056, pp.165-175

Samin, R., Goodaz, J. D., Muhammad, S. R., Firoozeh, F., Mahsa, H., and Sanaz, E. 2012. A Conceptual Study on the Country of Origin Effect on Consumer Purchase Intention. Canadian Center of Science and Education, Vol. 8(12), pp.205-215.

Hatane, Samuel dan Lianto, Adi Suryanata. 2014. Pengaruh Analisis eWOM, Brand Image, Brand Trust dan Minat Beli Produk Smartphone di Surabaya. Jurnal Universitas Kristen Petra Surabaya. Vol. 8. No. 2, ISSN 1907$235 X$.

Hidayanti, Tri Asih., Suharyono dan Dahlan Fanani. 2013. Pengaruh Citra Merek Terhadap Minat Beli Dan Keputusan Pembelian Konsumen.(Survei pada Mahasiswa Penghuni Ma'had Sunan Ampel Al-Aly UIN Malang Tahun Angkatan 2012/2013 yang Mengkonsumsi Mie Instan Merek Indomie). Jurnal Administrasi Bisnis. Vol. 2 No. 1 Mei 2013

Ika, Nuruni dan Kustini. 2011. Experiental Marketing, Emotional Branding, and Brand Trust and their Effect on Loyalty on Honda Motorcycle Product. Journal of Economics, Universitas Pembangunan Nasional, Vol. 14, No. 1, April 2011, pp. 19-28.

Sekaran, Uma. (2013). Research Methods for Buisiness. Jakarta. Salemba Empat

Tjiptono, Fandy. 2005. Pemasaran Jasa. Malang : Bayumedia Publishing

Utama, Made Suyana. 2016. Aplikasi Analisis Kuantitatif: Denpasar : CV. Sastra Utama.

Wu, M.-H. 2014. Relationships Among Source Credibility of Electronic Word of Mouth, Percieved Risk, and Consumer Behavior on Consumer Generated Media. Thesis, University of Massachusetts Amherst.

Wahyuni, N.L.G., dan G. Suparna. 2014. Pengaruh Citra merek dan Product Knowledge Terhadap Niat membeli Produk Tas Tiruan di Kota Denpasar. E- Jurnal Manajemen Universitas Udayana, h: 1022-1034.

Yana, Ravita Dwi., Surhayono dan Yusri Abdillah. 2015. Pengaruh Citra Merek Terhadap Kepuasan Pelanggan Dan Loyalitas Pelanggan (Survei Pada Konsumen Produk Busana Muslim Dian Pelangi Di Malaysia). Jurnal Administrasi Bisnis. Vol. 21 No. 1 